\title{
Changes of Grassland Rain Use Efficiency and NDVI in Northwestern China from 1982 to 2013 and Its Response to Climate Change
}

\author{
Juan Chang ${ }^{1}$, Jiaxi Tian ${ }^{1}$, Zengxin Zhang ${ }^{1,2, *}, X_{i}$ Chen ${ }^{2}$, Yizhao Chen ${ }^{1}$, Sheng Chen ${ }^{3}$ \\ and Zheng Duan ${ }^{4} \mathbb{D}$ \\ 1 Joint Innovation Center for Modern Forestry Studies, College of Biology and the Environment, \\ Nanjing Forestry University, Nanjing 210037, China; changjuan@njfu.edu.cn (J.C.); \\ tianjiaxi@njfu.edu.cn (J.T.); chenyzvest@gmail.com (Y.C.) \\ 2 State Key Laboratory of Hydrology-Water Resources and Hydraulics Engineering, Hohai University, \\ Nanjing 210098, China; xichen@hhu.edu.cn \\ 3 School of Atmospheric Sciences, Sun Yat-Sen University, Zhuhai 519082, China; chenshengbj@gmail.com \\ 4 Chair of Hydrology and River Basin Management, Technical University of Munich, 80333 Munich, Germany; \\ duanzheng2008@gmail.com \\ * Correspondence: zzhang@hhu.edu.cn; Tel.: +86-25-8542-8963
}

Received: 18 October 2018; Accepted: 15 November 2018; Published: 19 November 2018

check for updates

\begin{abstract}
The grasslands in arid and semi-arid regions rely heavily on the use of rain, thus, improving rain use efficiency (RUE) is essential for securing sustainable development of grassland ecosystems in these areas with limited rainfall. In this study, the spatial and temporal variabilities of RUE for grassland ecosystems over Northwestern China during 1982-2013 were analyzed using the normalized difference vegetation index (NDVI) and precipitation data. Results showed that: (1) Although grassland area has decreased gradually over the past 30 years, the NDVI in most areas showed that the vegetation was gradually restored; (2) The trends of RUE increased in the east of Northwestern China and decreased in the west of Northwestern China. However, the trends of RUE for the high-coverage grasslands (vs. low-coverage grassland) increased (decreased) significantly over the past 30 years. (3) The RUE for the grasslands was positively correlated with air temperature, while it was negatively correlated with the change of annual mean precipitation in northwestern China. Moreover, the obvious RUE increasing trends were found in the vegetation restoration areas, while the RUE decreasing trends appeared in the vegetation degradation areas. This study will be helpful for understanding the impacts of climate change on securing the sustainable development of grassland ecosystems in arid and semi-arid regions.
\end{abstract}

Keywords: grassland; vegetation restoration; degradation; rain use efficiency; NDVI

\section{Introduction}

Vegetation is an important part of a terrestrial ecosystem and plays an important role in global climate change [1,2]. The normalized difference vegetation index (NDVI) is a simple graphical indicator to monitor the change in vegetation by using remote sensing measurements [3]. It has been widely used in such large-scale vegetation dynamic monitoring such as global or continental studies. For example, Eastman et al. [4] used the seasonal trend analysis (STA) procedure to determine that over half $(56.30 \%)$ of land surfaces were found to exhibit significant trends, and the NDVI in the green season was balanced by decreases in the brown season. These areas were found primarily in grassland and shrubland regions. Laidler et al. [5] explored the relationship between the NDVI and percent-vegetation covers in a tundra environment, where variations in soil moisture, exposed soil, and gravel till 
have significant influence on spectral response, and hence, on the characterization of vegetation communities. Suzuki et al. [6] using 5-year (1987-1991) monthly means analyzed the NDVI distribution and its seasonal cycle to investigate it in relation to temperature and precipitation over Siberia and its surrounding regions. It was found that the vegetation degeneration is serious in many areas, for example, Ma et al. [7] reported that the NDVI decreased in the whole Northwest of China, and the vegetation degeneration was serious during the period 1990-1999. Ma et al. [8] also found that vegetation coverage degenerated seriously in most parts of Northwestern China during the period 1981-2001. However, some research has reported that the NDVI had an increasing trend in other areas, for example, Zhou et al. [9] founded that the NDVI increased in the Heihe River basin from 1999 to 2007.

Some studies have revealed that climate change and human activities might be the main driving factor affecting NDVI [10-13]. However, moisture might be one of the main factors determining the composition, distribution, and growth status of vegetation in arid and semi-arid regions [14]. The water use efficiency (WUE, ratio of carbon assimilated to water transpired) of vegetation plays an important role in determining the exchange of water between ecosystems and the atmosphere, and thus, affects the global water cycle. It also shapes the water-energy balance of ecosystems as a decrease in water fluxes may lead to an increase in surface temperature [15]. For example, Chen et al. [16] showed that the temperate Eurasian steppe WUE was on the rise in the middle part of the Eurasian continent, but that the grassland was recovering cannot be concluded due to climate changes during the period from 1999-2008. Precipitation is an essential factor in controlling biodiversity and ecosystem functioning of terrestrial biomes, especially for arid and semiarid ecosystems [17]. Rain use efficiency (RUE) is defined as the amount of biomass produced per unit of precipitation and is the key indicator for measuring the response of plant production to precipitation [18]. The RUE provides a useful index for improved understanding of the relationship between precipitation and vegetation productivity, as well as for evaluating the degradation of grasslands [14,17-19]. For example, Sahnoun et al. [20] using Modis level $2 \mathrm{G}$ data estimated RUE and determined environmental changes along a spatial gradient of arid lands in Southern Tunisia, and they found that this methodology provided a way to monitor changes in resilience induced by land-use in this arid region, as well as support detection of future desertification. Being the best indicator of vegetation cover change, RUE change has received wide attention from scientists.

Many studies of RUE in different regions have shown that RUE is affected by many factors such as temperature and precipitation [19,21,22]. For example, Hountondji [23] revealed the changes of RUE in the ongoing desertification process of West Africa and they found that the RUE over $49.5 \%$ of the Sahel region was stable, while the area under $38 \%$ declined and only $1.3 \%$ showed an upward trend during the years between 1982 to 1999. Webb et al. [24] reported that plant cover affects RUE through alterations in evapotranspiration rate: greater plant cover values lead to greater RUE. Gamoun [25] found that RUE tended to be higher during dry years and lower during wet years on Helianthemum kahiricum (loamy soils) in the desert rangelands of Tunisia. Mi et al. [26] also reported that RUE is positively (negatively) correlated with temperature (precipitation) in the Qinghai-Tibetan grassland. Wang [27] found that RUE has significant differences for the different vegetation cover types in the Tao River basin, and that RUE was negatively correlated with precipitation. Zhang et al. [28] analyzed the temporal and spatial variation of RUE in the Yellow River basin from 1998 to 2012, and they found that similar trends can be found for the NDVI and RUE in these areas. Kundu et al. [29] found that the regression slope of RUE mainly depends upon the dynamic condition of integrated NDVI and rainfall, and RUE has been used for monitoring vegetation degradation, and substantially, the process of desertification in western Rajasthan. Huxman et al. [30] reported that for vegetation RUE showed a downward trend as annual precipitation gradually increased from desert to steppe to forest. Paruelo et al. [31] found that RUE first rises and then falls, and peaks in areas with precipitation of $475 \mathrm{~mm} / \mathrm{a}$ based on the study of 11 temperate grassland ecosystems around the world. Sala et al. [17] thought that the RUE is the most important factor in controlling production by analyzing the 
data collected at 9500 locations across the central United States. Wessels et al. [32] used net primary productivity (NPP), RUE and Local NPP Scaling (LNS) to successfully detect the degraded areas in the Northern Provinces of South Africa as an indicator of land status.

Due to geographical location and climatic conditions, the type of vegetation is dominated by grassland in Northwestern China [33,34]. The degradation/restoration of grassland in Northwestern China is a hot issue in recent years. Xu et al. [35] found that the grassland of Maduo County was seriously degraded in 1994 and the degradation of grassland vegetation was the most serious from 1994 to 2001, and the degraded areas of grassland decreased greatly and the degradation rate eased in the source region of the Yellow River during 2001 to 2006 and 2006 to 2009. Xian et al. [36] found that the degraded areas were mainly concentrated on grassland areas dominated by animal husbandry in headwaters region of Northeastern Sichuan, and the growth areas were concentrated in the plateau areas less affected by human activities. In addition, scholars have found that warming and human activities such as overgrazing were the main causes of grassland degradation [33,37]. Although more and more studies of RUE have been done in recent years, RUE research is still relatively few in Northwestern China [38]. The grassland in arid and semi-arid regions relies heavily on the use of rain and improving RUE is necessary for securing sustainable development of grassland ecosystems in these areas [39].

Northwestern China is far away from the sea with less rainfall, and the vegetation type is mainly occupied by grassland [40]. Based on the time series NDVI data and meteorological data, this study aims to explore the temporal and spatial variations of RUE and its response to the vegetation restoration/degradation in Northwestern China. Our findings are expected to have important implications for understanding and predicting ecological impacts on global climate change and for management practices in arid and semiarid ecosystems in Northwestern China and beyond [41].

\section{Material and Methods}

\subsection{Study Area and Material}

The study area is located in Northwestern China with an area of about 4 million $\mathrm{km}^{2}$ (Figure 1). The terrain in the northwestern region is mainly plateaus, basins, and mountains, including the Tarim River Basin, the Qaidam Basin, the Inner Mongolia Plateau, and the Qilian Mountains [13]. Most of the areas are controlled by arid and semi-arid climates with little rain and strong evaporation, therefore, low vegetation coverage and serious land desertification is a major feature in Northwestern China. The geographical differentiation of the area is significant, and the vertical zonal and horizontal zonal characteristics of vegetation are obvious. Most of the areas are sensitive to climate change in China [42,43].

The NDVI dataset at a spatial resolution of $8 \mathrm{~km} \times 8 \mathrm{~km}$ and 15-day intervals were derived from GIMMS (Global Inventory Modeling and Mapping Studies group, https:/ / ecocast.arc.nasa. gov/data/pub/gimms/3g.v1/). The GIMMS NDVI 3g.v1 was generated from National Oceanic and Atmospheric Administration's (NOAA's) Advanced Very High-Resolution Radiometer (AVHRR) data, and the spatial resolution was $1 / 12^{\circ}$. The dataset spanned from July 1981 to December 2015. It was calibrated for sensor shift, cloud test, and removal of the effects of solar zenith angles and other factors [44]. The annual AVHRR GIMMS NDVI dataset used in this paper was obtained using the maximum value composite (MVC) method [45].

The land-use and land-cover change (LUCC) data came from the Resource and Environmental Science Data Center of the Chinese Academy of Sciences (http://www.resdc.cn/). The resolution of the national land use/cover data in 2010 was $1 \mathrm{~km}$, and the project was converted and cropped (2010 LUCC data). The data included six classifications: cultivated land, woodland, grassland, waters, construction land, and unused land. The grassland was further divided into three classifications: HCG (higher coverage grassland), MCG (middle coverage grassland) and LCG (low coverage grassland) (Table 1). 


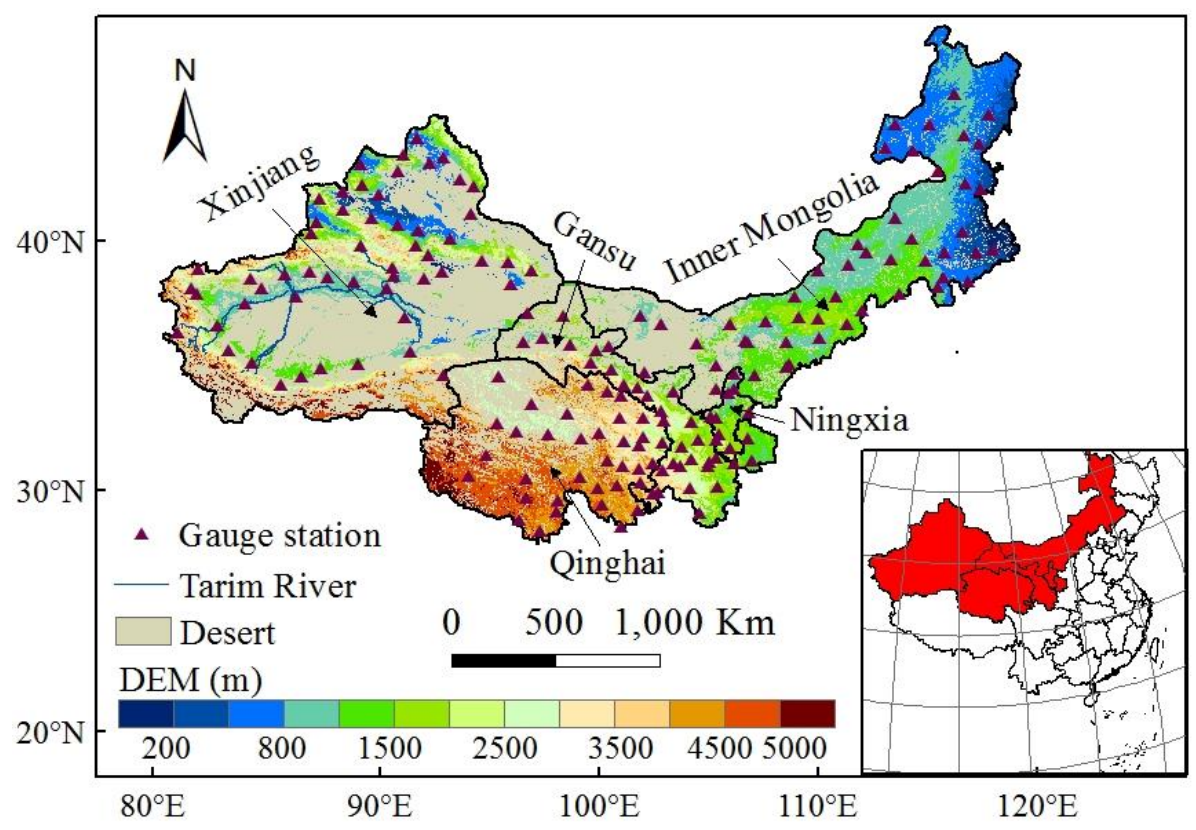

Figure 1. Study area maps and meteorological station location.

Table 1. Definition of three types of grassland in northwestern China (HCG: higher coverage grassland; MCG: middle coverage grassland; LCG: low coverage grassland).

\begin{tabular}{ccccc}
\hline Abbreviation & $\begin{array}{c}\text { Vegetation } \\
\text { Coverage (\%) }\end{array}$ & Grassland Type & $\begin{array}{c}\text { Water and Heat } \\
\text { Conditions }\end{array}$ & $\begin{array}{c}\text { Grassland } \\
\text { Characteristics }\end{array}$ \\
\hline HCG & $>50$ & Natural, Improved & Better & $\begin{array}{c}\text { Growing densely } \\
\text { MCG }\end{array}$ \\
LCG & $5-50$ & Natural, Improved & Insufficient & $\begin{array}{c}\text { Sparse vegetation } \\
\text { Sparse vegetation }\end{array}$ \\
\hline
\end{tabular}

The temperature and precipitation data were derived from 183 meteorological stations in China from 1982 to 2013 provided by the China Meteorological Data Network.

\subsection{Methodology}

The RUE and the ratio of NPP to precipitation could be a critical indicator for evaluating the response of primary productivity to variability of rainfall in arid and semi-arid ecosystems [14,18]. According to studies, accumulated NDVI is closely related to NPP in arid and semi-arid regions $[15,17,18,46,47]$. Therefore, in the study area we used the accumulated NDVI to calculate the RUE instead of the NPP value in the growing season. The growing season starts from April and ends in October according to the monthly mean temperature and precipitation in this study area.

The RUE was calculated as follows (1):

$$
R U E=\frac{\sum_{1}^{i} N D V I_{i}}{\sum_{1}^{i} P_{i}}
$$

where $i$ refers to the month (from April to October).

The MVC method was used to synthesize the monthly NDVI image data, and the average method was used to calculate the NDVI value of each grid in the growing season. The spatial distribution from 1982 to 2013 was calculated by the Kriging interpolation method in ArcGIS.

The linear regression analysis of NDVI and the year was carried out to obtain the linear change trend values of NDVI from pixel to cell to indicate whether the spatial variation characteristics and 
change trends of vegetation coverage was significant, and then counted the ratio of the pixels of each level to the total number of pixels. The RUE used the same methods.

The trend of change is divided into Equation (2):

$$
b=\frac{n \times \sum_{i=1}^{n} i \times N D V I_{i}-\sum_{i=1}^{n} i \sum_{i=1}^{n} N D V I_{i}}{n \times \sum_{i=1}^{n} i^{2}-\left(\sum_{i=1}^{n} i\right)^{2}}
$$

where $b$ refers to the trend of change, i.e., slope; $b>0$ means increasing trend, $b<0$ means decreasing trend; $i$ refers to year; $n$ refers to length of time. The significance test of the slope was performed by t-test [48].

In order to study the influencing factors of RUE change, the Pearson correlation analysis method was used to analyze the correlation between the RUE and the simultaneous temperature data, and the correlation coefficients were obtained.

The trend of change is divided into Equation (3):

$$
\mathrm{r}_{x y}=\frac{\sum_{i=1}^{n}\left[\left(x_{i}-\bar{X}\right)\left(y_{i}-\bar{Y}\right)\right]}{\sqrt{\sum_{i=1}^{n}\left(x_{i}-\bar{X}\right)^{2} \sum_{i=1}^{n}\left(y_{i}-\bar{Y}\right)^{2}}}
$$

where $i$ refers to year; $n$ refers to length of time; $\bar{X}$ refers to average RUE value, $\bar{Y}$ refers to average temperature value; $\mathrm{r}_{x y}$ refers to the correlation coefficient between $x$ and $y ; \mathrm{r}_{x y}>0$ means positive correlation, $r_{x y}<0$ means negative correlation. The significance test of the slope was performed by $t$-test.

The meteorological stations in Northwestern China are unevenly distributed, with the east and central regions being denser and the regions near the deserts being very sparse. The Kriging interpolation method was used to interpolate the pointed-based rainfall to obtain spatial patterns of rainfall in the study areas following [49].

Simple linear regression was used in this paper for long-term linear trend test. The simple linear regression method is a parametric $t$-test method, which consists of two steps, fitting a linear simple regression equation with the time $t$ as independent variable and $Y$ as dependent variable; testing the statistical significance of the slope of the regression equation by the $t$-test.

A simple but practical way of sensitivity analysis is to calculate and plot the relative changes of an input variable against the resultant relative change of the output variable as a curve (i.e., the sensitivity curve), then the corresponding relative change of the outcome can easily be read from the sensitivity curve for a certain relative change of the variable [50]. This method has been used by many authors. In this study, the variable (i.e., NDVI and meteorological) used the following equation:

$$
X=X+\Delta X ; \Delta X=0, \pm 5 \%, \pm 10 \%, \pm 15 \%, \pm 20 \%
$$

where $X$ is the variable.

\section{Results}

\subsection{The Changes of RUE for the Grassland in Northwestern China}

Figure 2 shows the spatial distribution of annual mean RUE for the grasslands in Northwestern China from 1982 to 2013. In most regions, the annual mean RUE for all of the grassland was higher than that of HCG, MCG, and LCG areas. It also can be found that the lower RUE values appeared in the vegetation degradation areas, while the higher RUE values can be found in the vegetation restoration areas (Figure 2a). For high coverage grassland area, the RUE varied between 0.005 and 0.015, and higher RUE value can be found near the Hulunbeier grasslands and Horqin grasslands (Figure 2b). However, for RUE in the MCG areas, the RUE value was as high as 0.027 and the higher RUE values were located more on the edge of the Taklimakan Desert where precipitation was rare. 
Moreover, the RUE value was also higher in the Northeastern Inner Mongolia Autonomous Region (Figure 2c). Compared with the HCG and MCG, the higher RUE value appeared in Xinjiang Province, but lower RUE values could be found in Southwestern Qinghai Province for the LCG areas (Figure 2d).

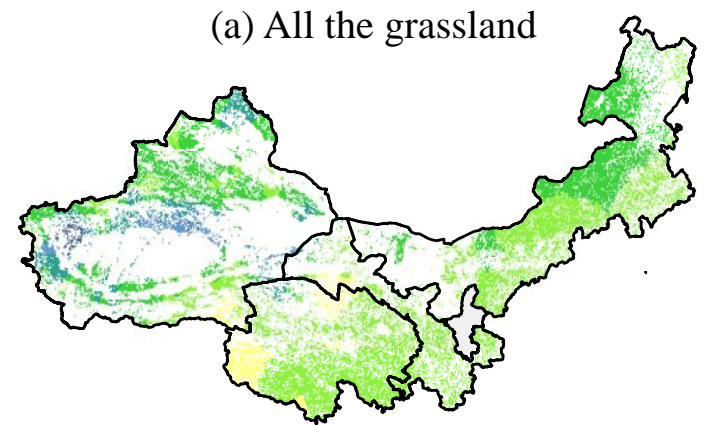

(c) Moderate coverage

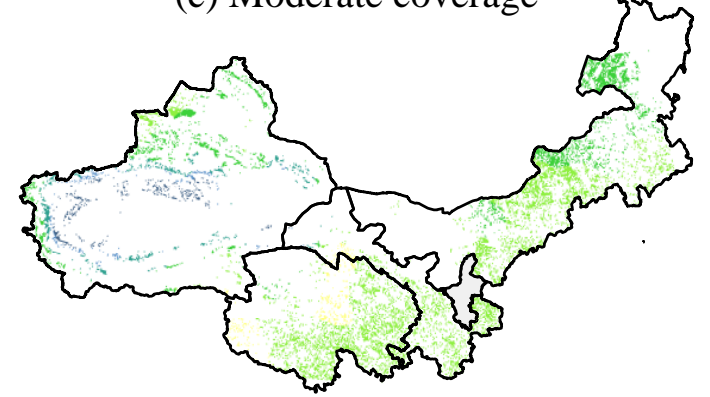

(b) High coverage

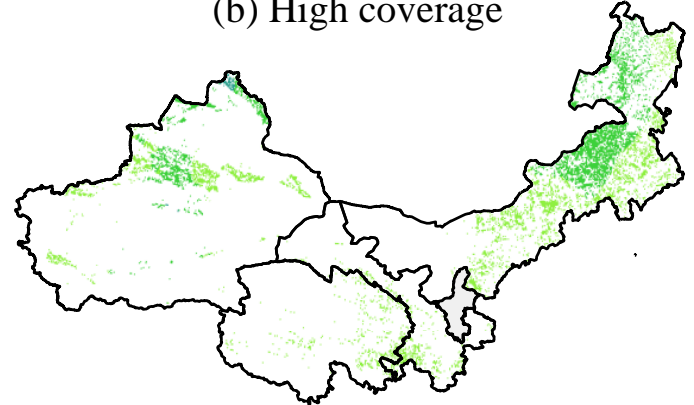

(d) Low coverage

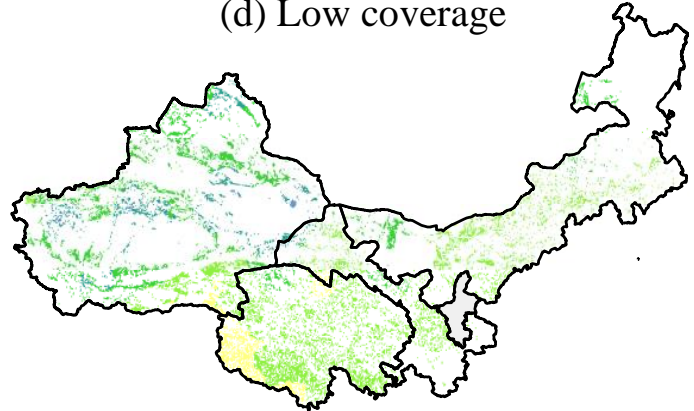

RUE*100

$$
\begin{array}{lllll}
0.5 & 1 & 1.5 & 2 & 2.5
\end{array}
$$

Figure 2. The spatial distribution of annual mean rain use efficiency (RUE) in Northwestern China from 1982 to 2013. (a) All the grassland; (b), HCG; (c), MCG; (d), LCG.

In order to reveal the long-term changes of RUE for the grassland in Northwestern China from 1982 to 2013, the RUE trends are shown in Figure 3. As shown in Figure 3a, the RUE for all the grasslands showed obviously increasing trends in the eastern region of Northwestern China, while it decreased in the western areas. The number of pixels with increasing trends of RUE $39.91 \%$ of the total number of pixels, of which $9.26 \%$ of the pixels increased significantly. However, the number of pixels with decreasing trends of RUE were 39.61\% indicating that the grassland RUE trend was decreasing. As for the HCG, the number of pixels with increasing trends was as high as $62.23 \%$ of the total number of pixels, of which $17.02 \%$ of the pixels increased significantly, while the number of pixels with decreasing trend was $22.87 \%$ (Figure $3 b$ ). It can be found that the percent of pixels with RUE changes for the MCG and LCM grasslands were lower than that of HCG grasslands (Figure 3c,d). The percent of pixels with RUE increasing trends were $41.82 \%$ and $23.26 \%$, respectively. However, the percent of pixels with decreasing trends was as high as $58.13 \%$ for LCG grasslands, which was higher than that of HCG and MCG grassland (Table 2).

Table 2. The percent of pixels with RUE changes for the grasslands during the past 30 years in Northwestern China (Unit: \%).

\begin{tabular}{cccccc}
\hline $\begin{array}{c}\text { Grassland } \\
\text { Type }\end{array}$ & Increased & $\begin{array}{c}\text { Increased } \\
\text { Significantly }\end{array}$ & No Change & Decreased & $\begin{array}{c}\text { Decreased } \\
\text { Significantly }\end{array}$ \\
\hline HCG & 62.23 & 17.02 & 14.90 & 22.87 & 5.85 \\
MCG & 41.82 & 9.55 & 25.46 & 32.72 & 7.27 \\
LCG & 23.26 & 5.43 & 18.60 & 58.13 & 27.13 \\
All the & 39.91 & 9.26 & 20.48 & 39.61 & 14.72 \\
grasslands & & & & & \\
\hline
\end{tabular}


Figure 4 shows the annual mean and linear trends of RUE. The grassland RUE in Northwestern China showed a decreasing trend, and the highest (lowest) RUE value occurred in the year of 1997 (1998). As for the HCG, the RUE showed a significantly increasing trend, and the RUE value varied greatly during the period of 1996-1999 (Figure 4b). However, the RUE showed a significantly decreasing trend for the LCG areas (Figure 4 d).

(a) All the grassland

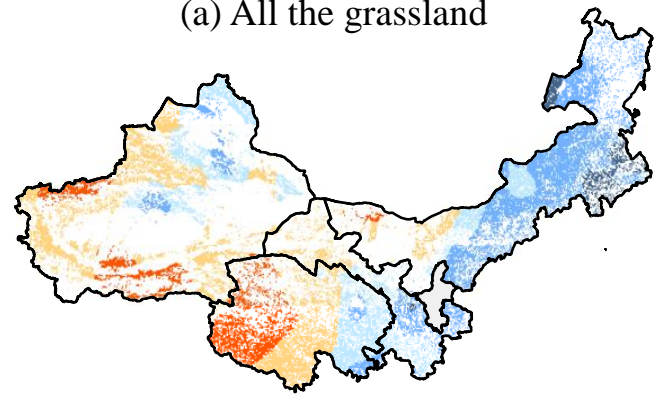

(c) Moderate coverage

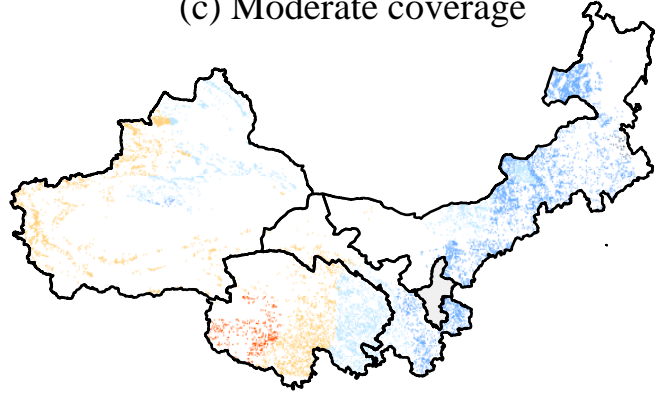

RUE trends

Decreasing significantly Decreasing (b) High coverage

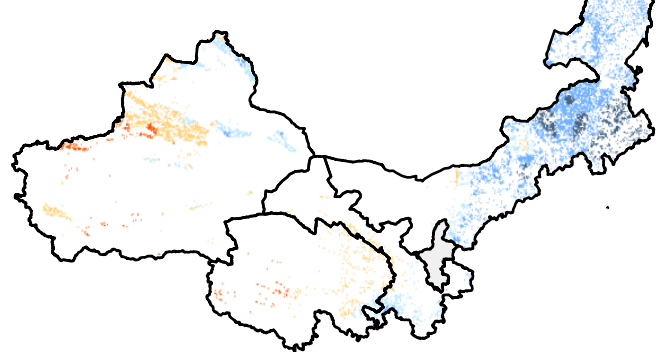

(d) Low coverage

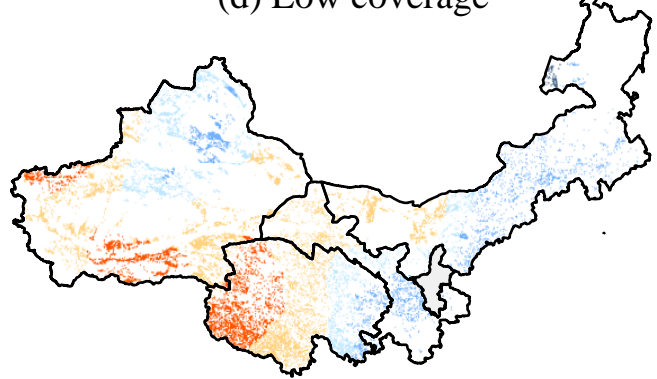

Figure 3. The spatial changes of RUE in Northwestern China from 1982 to 2013. (a) All grasslands; (b) HCG; (c) MCG; (d) LCG.
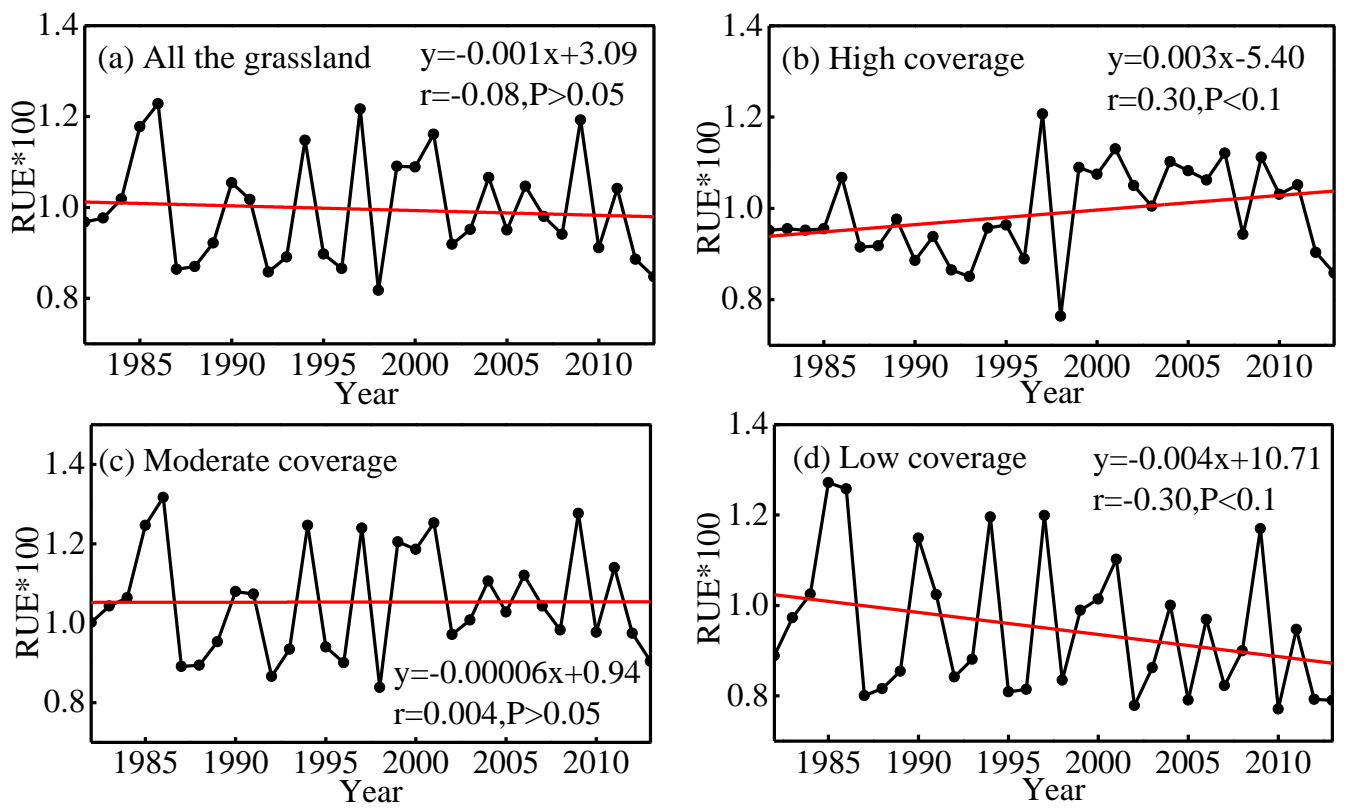

Figure 4. The annual mean and linear trends of RUE in Northwestern China from 1982-2013. (a) All grasslands; (b) HCG; (c) MCG; (d) LCG. 


\subsection{The Relations between RUE and Vegetation Restoration/Degradation in Northwestern China}

The status of LUCC in Northwestern China in the year of 2010 is shown in Figure 5. This figure clearly shows that the grassland was the main type of land use in Northwestern China and it can be found that the grasslands occupy nearly $40 \%$ of the land surface of the Northwestern China. The grassland was mainly distributed in the central regions of Inner Mongolia Plateau, Ningxia Province, most parts of Gansu Province and Qinghai Province, and the western part of Xinjiang Autonomous Region. Most parts of Xinjiang were deserts, Taklimakan Desert is in the Xinjiang, and the grassland in this area was distributed outside the desert. From this figure, it can also be found that the higher NDVI values were in the northeast and south areas; however, lower NDVI values appeared in the west areas where distributes of large deserts are found (Figure 6).

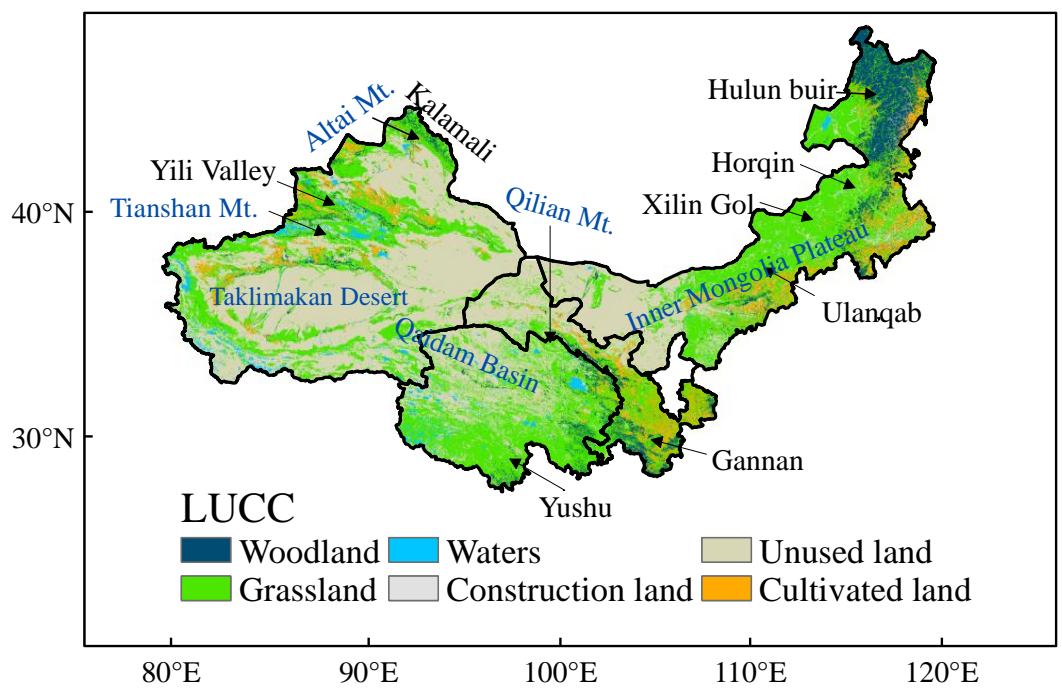

Figure 5. The land-use and land-cover change (LUCC) classification in the year of 2010.

To reveal the changes in vegetation coverage for the grasslands in Northwestern China, the features of HCG, MCG, and LCG were analyzed in this paper. The grass coverage rate for the HCG, MCG, and LCG was $>50 \%, 20 \sim 50 \%$, and 5 20\%, respectively (Table 2). It can be seen from Table 3 that the LCG areas were obviously bigger than that of the HCG and MCG areas in the study area. Overall, the grassland areas in Northwestern China showed a decreasing trend during the past 30 years and the grassland areas decreased by $25,187 \mathrm{~km}^{2}$ from 1990 to 2010. In 1990, the grassland area in the northwest region accounted for $39.59 \%$ of the total area. By 2010, the grassland area accounted for $38.96 \%$ of the total area of the northwest region, and the area decreased by $0.63 \%$. It can also be found that the HCG, MCG, and LCG areas decreased by 9305, 4679, and 11,203 $\mathrm{km}^{2}$ during the past 30 years, respectively. The HCG decreased from $10.59 \%$ to $10.36 \%$, a total of $0.23 \%$; MCG decreased from $12.88 \%$ to $12.76 \%$, a total of $0.12 \%$; and LCG decreased the most, a total of $0.28 \%$. Therefore, it can be inferred that the grassland area in Northwestern China has decreased gradually in the past 30 years.

Table 3. Grassland and three types of grassland areas in Northwestern China (Area, unit: $\mathrm{km}^{2}$; Percent, unit: \%).

\begin{tabular}{|c|c|c|c|c|c|c|c|c|}
\hline \multirow{2}{*}{ Year } & \multicolumn{2}{|c|}{ All Grasslands } & \multicolumn{2}{|c|}{ HCG } & \multicolumn{2}{|c|}{ MCG } & \multicolumn{2}{|c|}{ LCG } \\
\hline & Area & Percent & Area & Percent & Area & Percent & Area & Percent \\
\hline 1990 & $1,564,993$ & 39.59 & 418,786 & 10.59 & 509,024 & 12.88 & 637,183 & 16.12 \\
\hline 2000 & $1,548,210$ & 39.18 & 410,447 & 10.39 & 508,580 & 12.87 & 629,183 & 15.92 \\
\hline 2005 & $1,539,873$ & 38.97 & 409,743 & 10.37 & 504,098 & 12.76 & 626,032 & 15.84 \\
\hline 2010 & $1,539,806$ & 38.96 & 409,481 & 10.36 & 504,345 & 12.76 & 625,980 & 15.84 \\
\hline $\begin{array}{c}2010 \text { minus } \\
1990\end{array}$ & $-25,187$ & -0.63 & $-9,305$ & -0.23 & $-4,679$ & -0.12 & $-11,203$ & -0.28 \\
\hline
\end{tabular}


The annual mean NDVI for the grasslands from 1982 to 2013 is shown in Figure 6. It can be found that higher NDVI values appeared in the Hulunbeier grassland, Yili grassland, and lower NDVI values can be found on the edge of the Tarim Basin and Qaidam Basin. In most regions, the NDVI value varied between 0.1 and 0.5 and the NDVI value was as high as 0.73 in the Yili Valley grasslands (Figure 6a).

The HCG was distributed in the Hulun Buir grasslands, the Horqin grasslands, the Ulanchabu grasslands, the grasslands in the Yili Valley, and the Kalamali Mountains grasslands in the Altay Region and the Qilian Mountain grasslands. For the HCG grassland areas, higher NDVI values were mainly distributed in the Hulun Buir grasslands and the Horqin grasslands (Figure 6c). Higher NDVI values appeared in the Qilian Mountain grasslands, Yushu grasslands, and the Gannan grassland area in the MCG grassland area (Figure 6e). However, the NDVI value varied greatly in most southern parts of Gansu Province and Qinghai Province (Figure 6g). As can be seen from Figure 6b, compared to 1982, the grassland in the northwestern region was gradually increasing, and three types of grasslands also showed increasing trends (Figure 6d,f,h).

(a) Annual mean for all the grassland

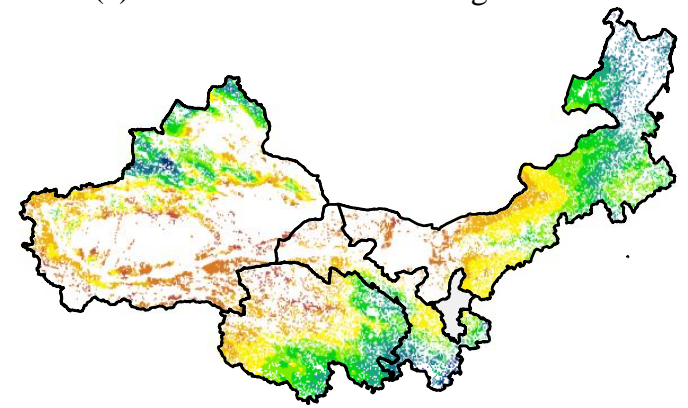

(c) Annual mean for High coverage

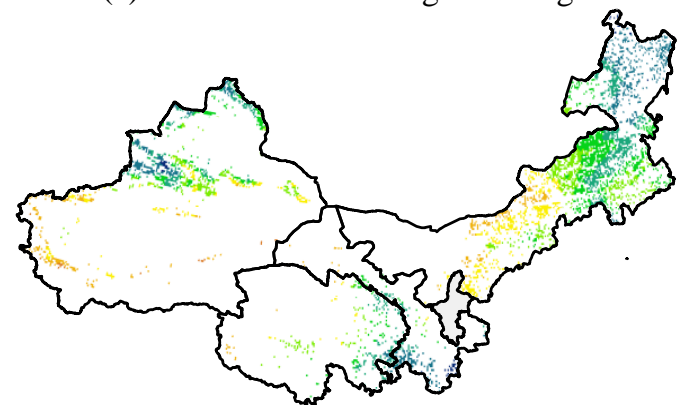

(e) Annual mean for Moderate coverage

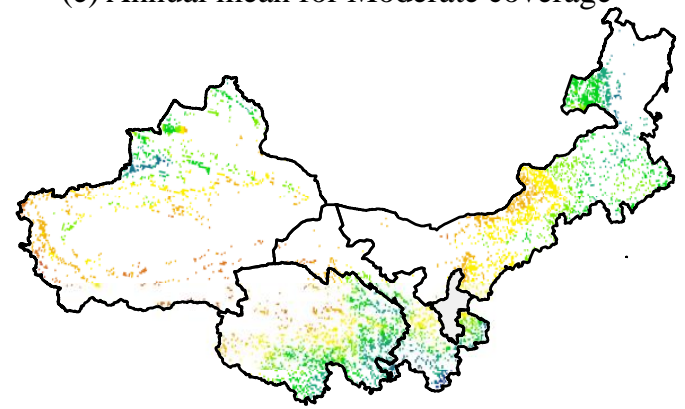

(b) 2013 minus 1982 for all the grassland

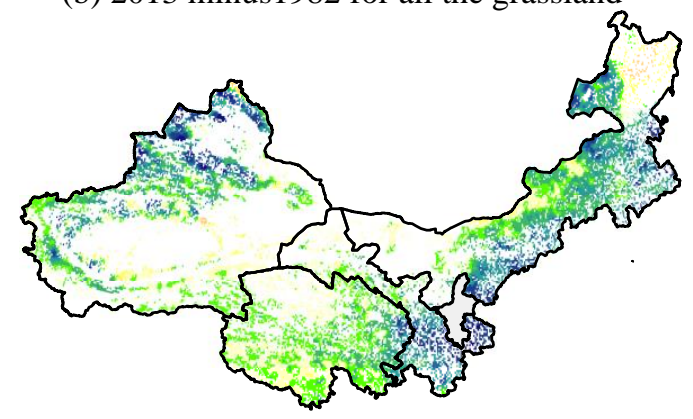

(d) 2013 minus 1982 for High coverage

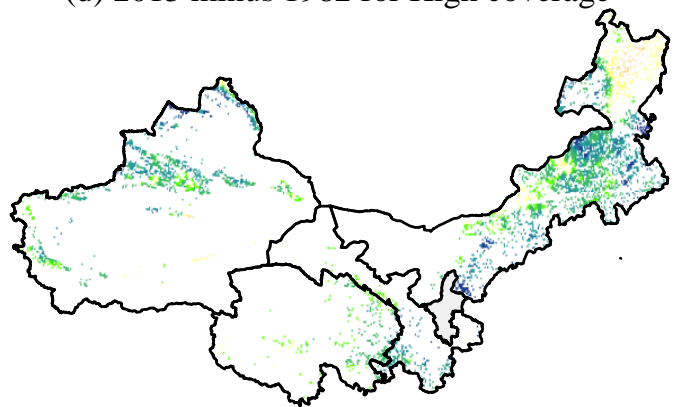

(f) 2013 minus 1982 for Moderate coverage

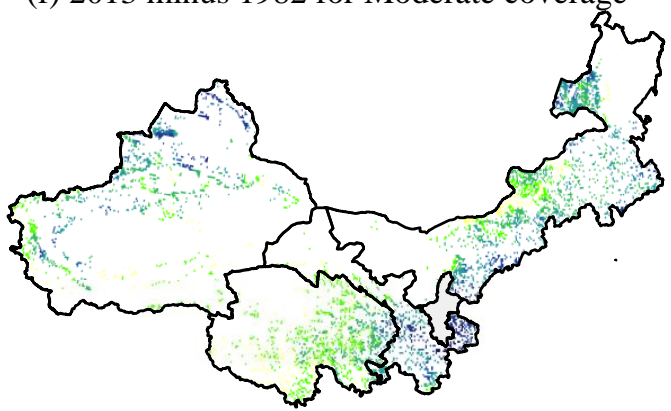

Figure 6. Cont. 
(g) Annual mean for Low coverage

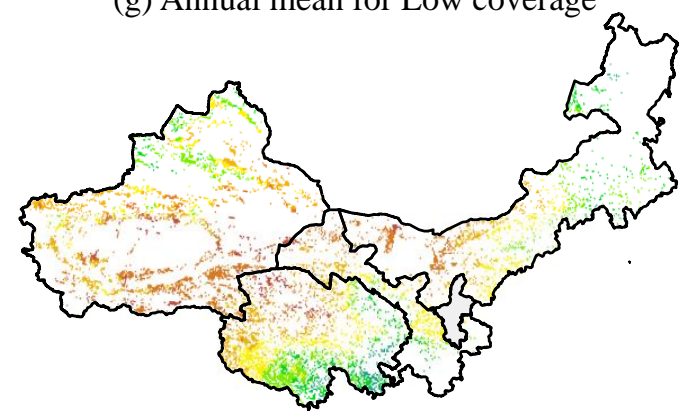

NDVI Value (h) 2013 minus 1982 for Low coverage

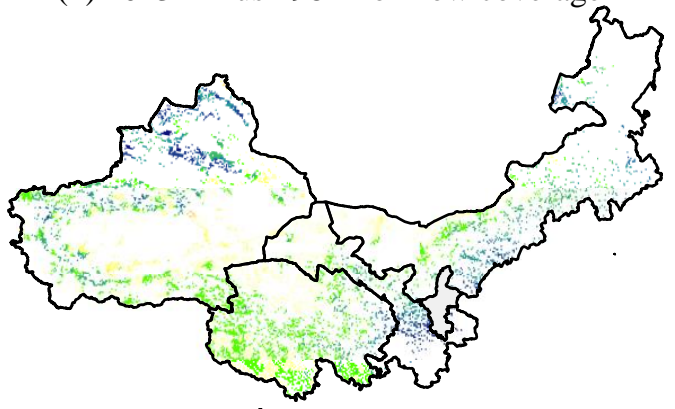

NDVI Value

$-0.05-0.0200 .020 .050 .080 .10 .15$

Figure 6. The spatial distribution of annual mean NDVI for the growing season from 1982 to 2013 and the NDVI differences between the 2013 and 1982 in the northwest China. (a,c,e,g), The annual mean NDVI for all the grasslands, HCG, MCG and LCG, respectively; (b,d,f,h), The NDVI differences between 2013 and 1982 for all the grasslands, HCG, MCG and LCG, respectively.

In this study, we defined the change trend of NDVI $r>0.1$ as restoration, $r>0.34$ as significant restoration; $\mathrm{r}<-0.1$ as degradation, and $\mathrm{r}<-0.34$ as significant deterioration. Figure 7 shows that the long-term trends of grassland restoration/degradation during the period from 1982-2013. It can be found that the NDVI exhibits obvious increasing trends for the whole Northwestern China during this period, especially in the areas for the Ningxia Province, Tianshan and Altai Mountains areas. The results indicated that the vegetation restoration appeared in most of Northwestern China during the past 30 years. According to the statistical analysis of pixels, the number of pixels with NDVI increasing was $59.1 \%$ of the total number of pixels, of which $29.73 \%$ was significantly, and the proportion was $18 \%$ for the pixels with decreasing trends, and of which $4.12 \%$ decreased significantly for the high-coverage grassland (Figure 7b). Similar results can be found in MCG, LCG, and all the grassland types (Figure 7c,d). However, it was clearly observed that the vegetation degraded seriously in the low-coverage grasslands. For example, the pixels of NDVI with decreasing trends in the whole region were as high as $33.38 \%$ of the total number of pixels, of which $20.5 \%$ of the pixels showed significant decreasing trends for the low coverage grassland (Table 4). Moreover, the vegetation degraded areas for the LCG appeared more around the Taklimakan desert which indicated that the grassland degraded seriously in the western fragile ecology region.

From Figure 7, it can be found that the NDVI increased obviously during the periods 1982-1998 and 2009-2013 for the HCG, MCG, LCG, and all the grasslands, while the NDVI decreased in the 2000s. However, the changes of annual mean NDVI for all the types of grasslands in Northwestern China showed significantly increasing trends during this period. Although the NDVI in some areas showed decreasing trends during the past 30 years, especially for the low coverage grassland which indicates that overall the vegetation restored significantly for the grassland.

(a) All the grassland

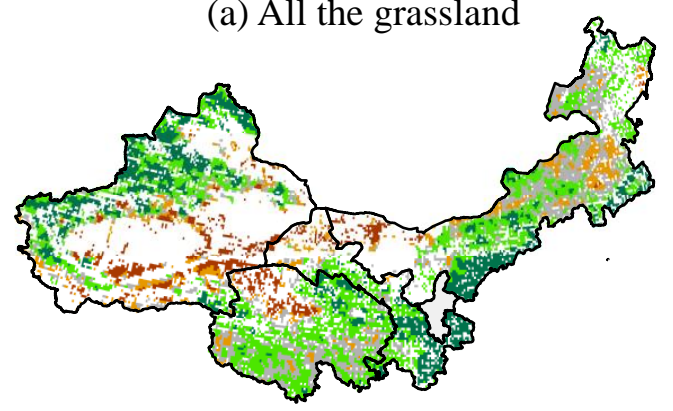

(b) High coverage

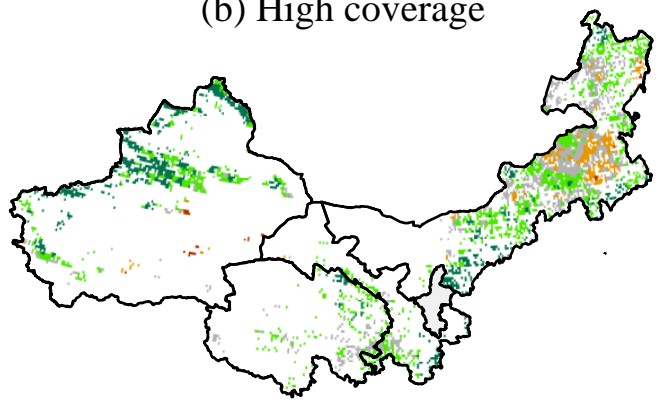

Figure 7. Cont. 

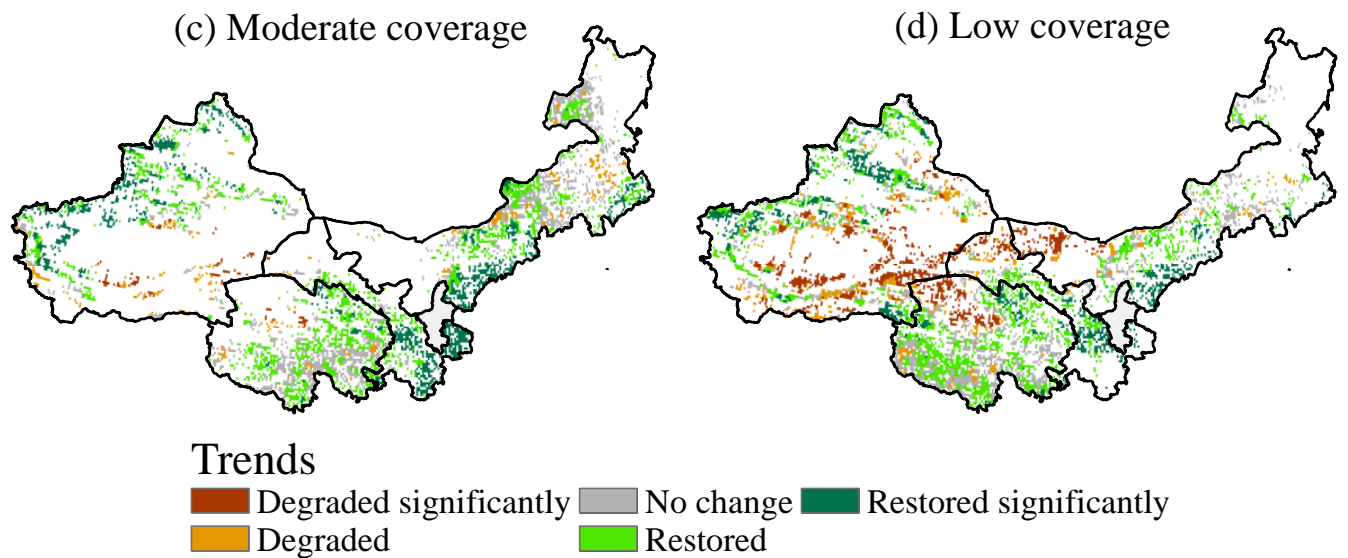

Figure 7. The grassland normalized difference vegetation index (NDVI) trends for the growing season in Northwestern China from 1982 to 2013. (a) All the grasslands; (b) HCG; (c) MCG; (d) LCG.

Table 4. The percent of pixels with NDVI changes for the grassland during the past 30 years in Northwestern China (Unit: \%).

\begin{tabular}{cccccc}
\hline $\begin{array}{c}\text { Grassland } \\
\text { Type }\end{array}$ & Increased & $\begin{array}{c}\text { Increased } \\
\text { Significantly }\end{array}$ & $\begin{array}{c}\text { No } \\
\text { Change }\end{array}$ & Decreased & $\begin{array}{c}\text { Decreased } \\
\text { Significantly }\end{array}$ \\
\hline HCG & 59.10 & 29.73 & 22.90 & 18.00 & 4.12 \\
MCG & 61.82 & 34.87 & 19.58 & 18.60 & 5.88 \\
LCG & 50.29 & 27.44 & 16.33 & 33.38 & 20.50 \\
$\begin{array}{c}\text { All the } \\
\text { grasslands }\end{array}$ & 56.87 & 30.92 & 19.11 & 24.02 & 11.02 \\
\hline
\end{tabular}

\subsection{The Relations between RUE and Climate Change in Northwestern China}

The impact of climate change on vegetation water use efficiency is very important for water resources management. Figure 8a shows the spatial distribution of mean annual precipitation for the vegetation growing season in Northwestern China. More than $300 \mathrm{~mm}$ of precipitation appeared in the eastern and southeastern regions, and less than $100 \mathrm{~mm}$ of precipitation distributed in the northwestern region where the desert occupied most of the area. The precipitation showed an increasing trend in the southwestern region, and the precipitation increased significantly in the Tianshan Mountains, Yinshan Mountains, and the Qinghai Province. The decreasing trends for precipitation appeared in the Greater Khingan Mountains, the Tarim Basin, and the Altai Mountains (Figure 8b). Figure 8c shows the distribution of the annual mean temperature. It can be found that the highest temperature appeared in the Taklamakan Desert region where the temperature was as high as $25^{\circ} \mathrm{C}$. The higher temperature (above $15^{\circ} \mathrm{C}$ ) was mainly located in the source region of the Yellow River, the Qilian Mountains, and the Kunlun Mountains. However, the lower temperatures were found in Qinghai Province. Moreover, it was found that the temperatures showed significant increasing trends in the whole of Northwestern China from 1982 to 2013 (Figure 8d). 

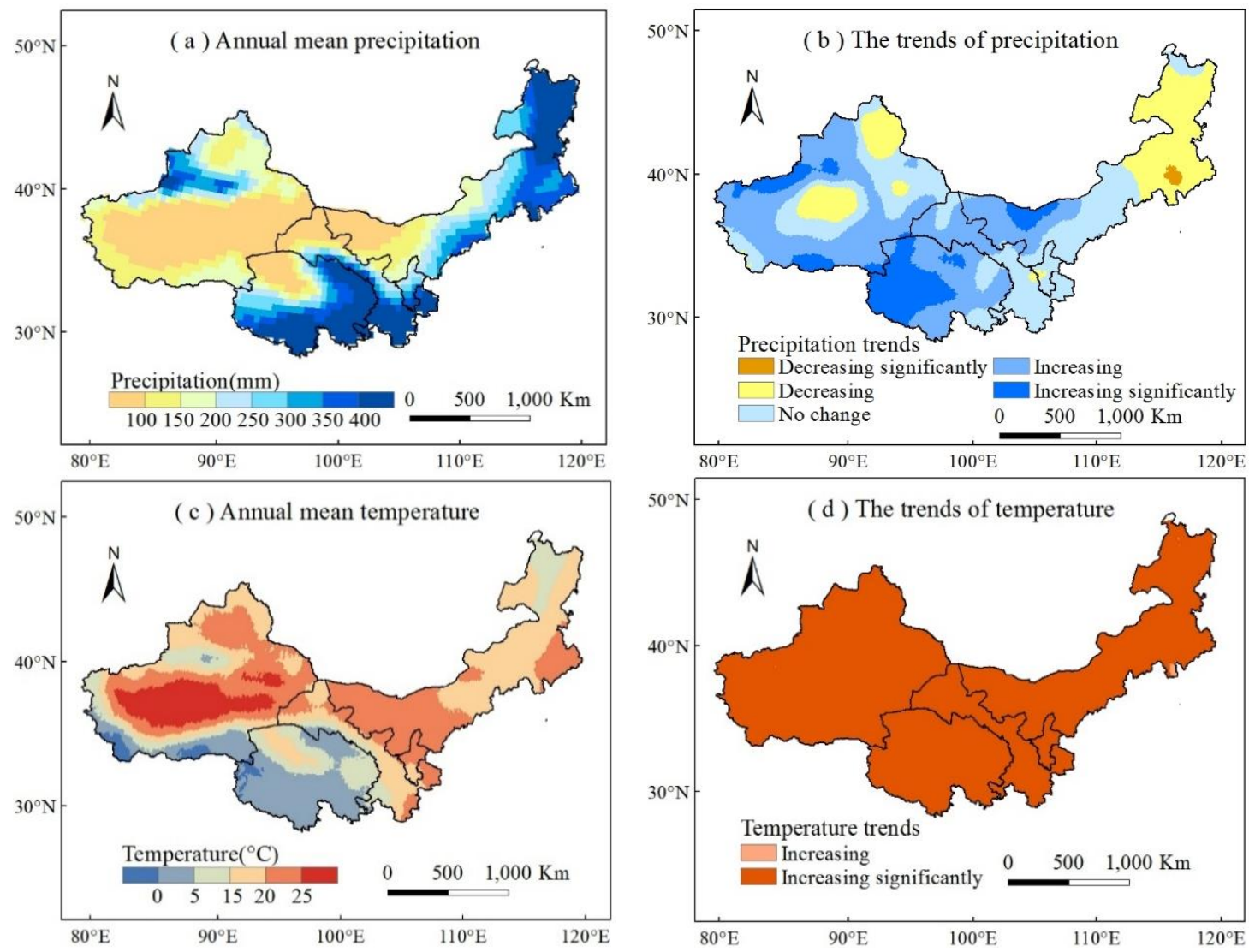

Figure 8. The spatial distribution and spatial change of precipitation and temperature for the growing season in Northwestern China from 1982 to 2013. (a) Annual mean precipitation; (b) The trends of precipitation; (c) Annual mean temperature; (d) The trends of temperature

Figure 9 shows the precipitation and temperature variabilities in northwestern China during the past 30 years. The increasing trend of precipitation was gentle from 1982 to 2013, but there was a large fluctuation from 1996 to 2003. However, the temperature showed a significant increasing trend. The lowest temperature appeared in the year of 1993, and the highest temperature appeared in the year of 1998.

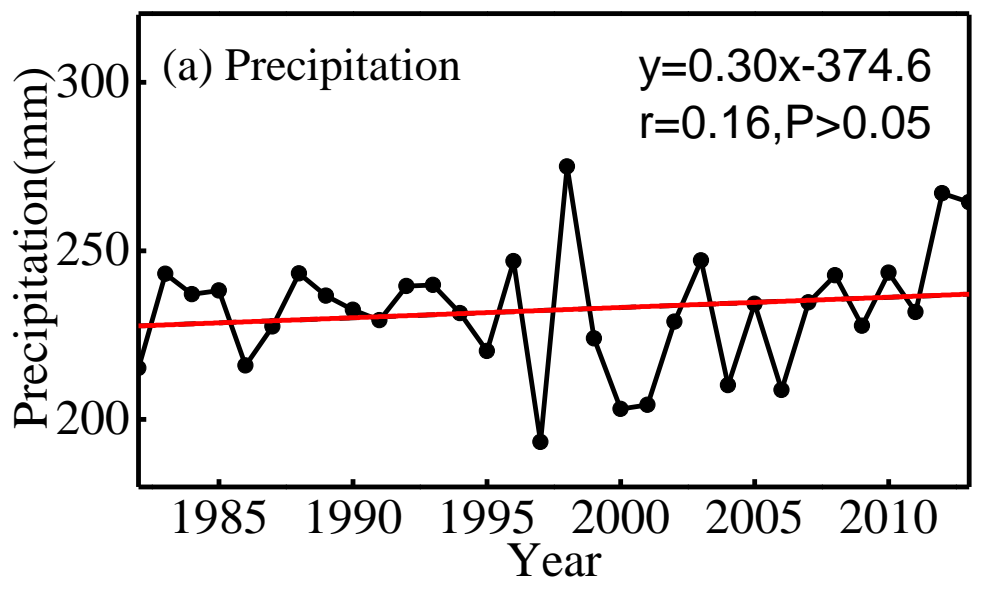

Figure 9. Cont. 


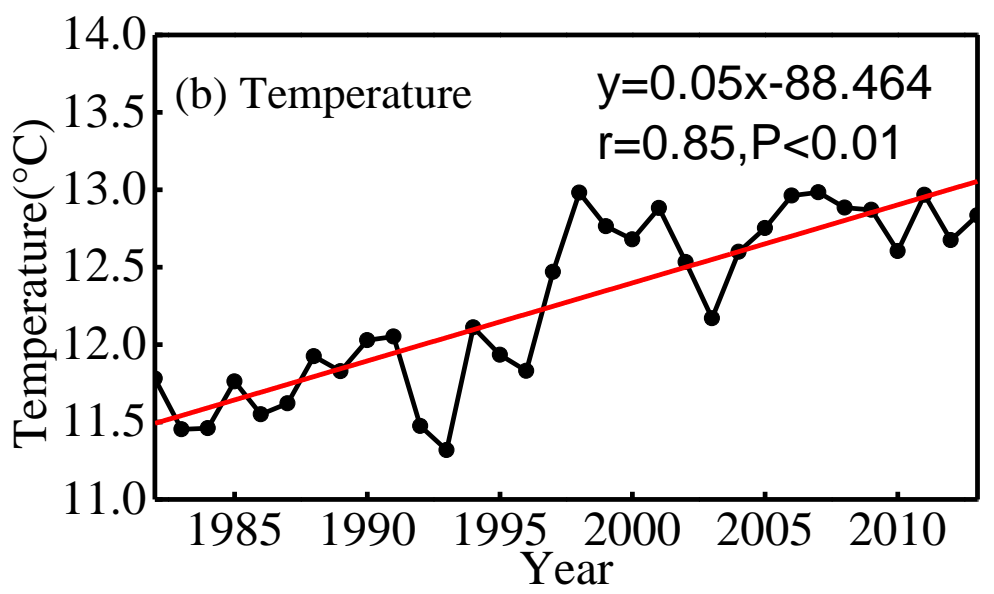

Figure 9. The annual mean and linear trends of precipitation and temperature for the growing season from 1982 to 2013. (a) Precipitation; (b) Temperature.

Figure 10 shows the correlations between RUE and temperature for the grasslands. The results showed that there was good relationship between the RUE and temperature for the grasslands. For example, the RUE for all the grasslands increased obviously with the increasing temperature, and the increasing rate for the RUE sped up when the temperature was higher than $15^{\circ} \mathrm{C}$ (Figure 10a). Similar results can be found with the MCG and LCG grassland (Figure 10c,d). It also can be found that the RUE and temperature for the HCG grasslands had a good linear relationship (Figure 10b), while the exponential relationship can be found in the MCG, LCG, and all the grasslands. Although the correlations between the RUE and temperature were significant for the grasslands, the highest correlation coefficient $(C C)$ values $(C C=0.72)$ can be found in the MCG grasslands and the lowest $C C$ values appeared in the HCG grasslands $(C C=0.20)$.
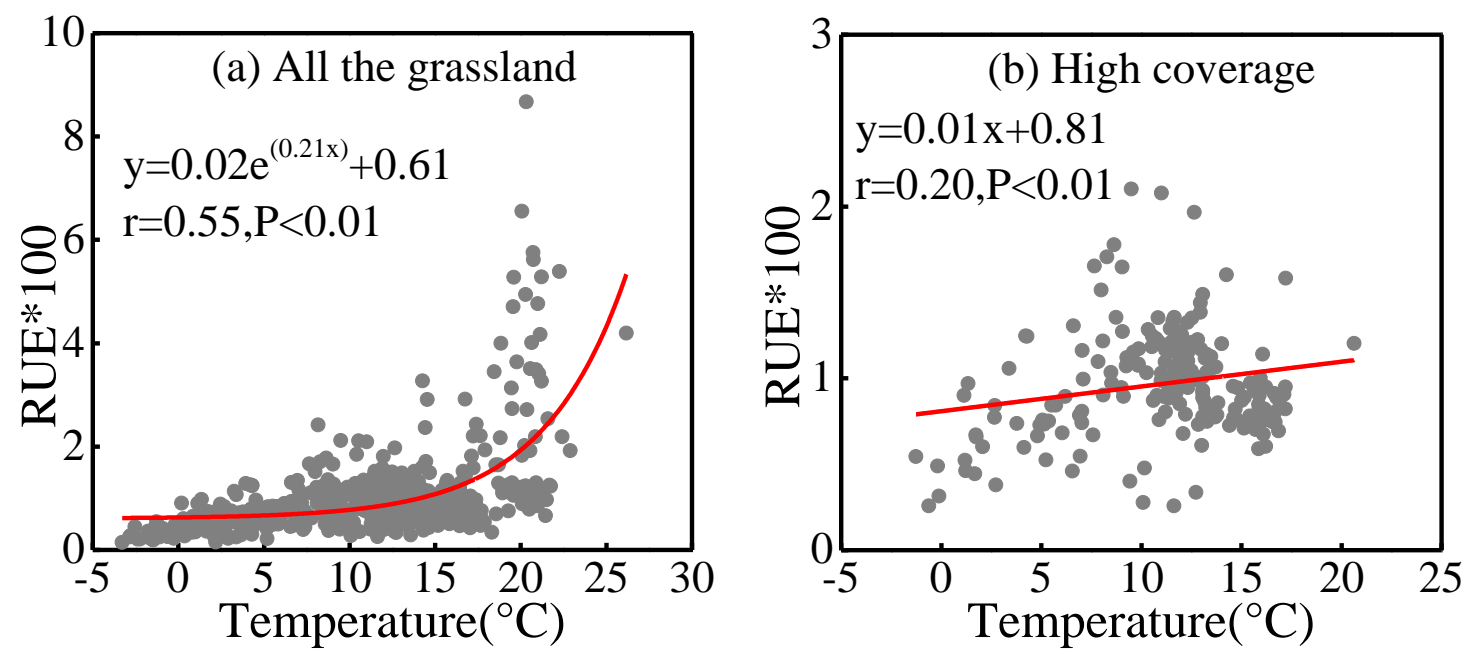

Figure 10. Cont. 

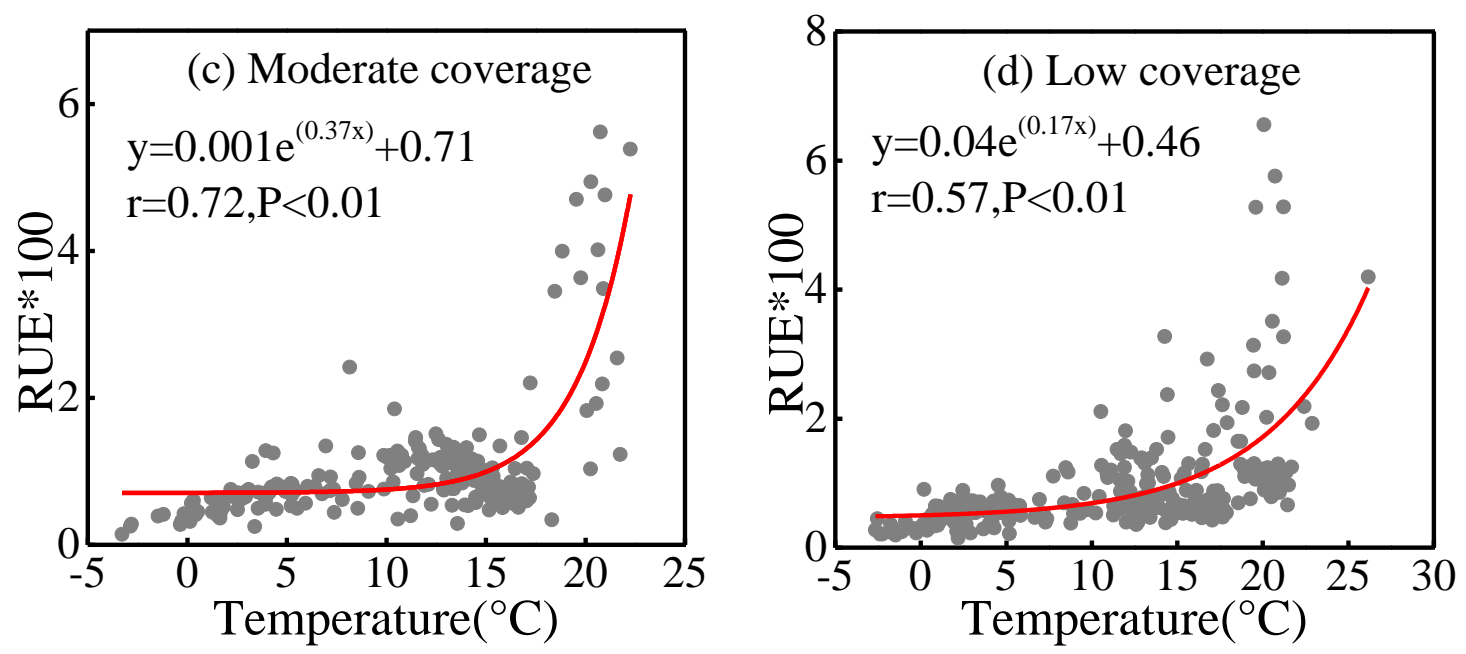

Figure 10. The correlation between RUE and temperature. (a) All the grasslands; (b) HCG; (c) MCG; (d) LCG.

The sensitivity of RUE with the NDVI and precipitation changes were analyzed and the results are shown in Figure 11. The RUE was more sensitive to the changes of precipitation. It was found that the RUE was negatively correlated with the precipitation while it was positively correlated with the NDVI changes. Thus, it can be concluded that RUE might change with the vegetation restoration/degradation in Northwestern China. Moreover, the RUE showed obvious increasing trends in the vegetation restoration areas, while the decreasing trends for the RUE can be found in the vegetation degradation areas as a whole. However, unlike the above relations between the RUE and vegetation restoration/degradation, the RUE in the Tianshan Mountains and Western Qinghai decreased over the past 30 years, while the vegetation had obvious restored trends. The RUE in the Horqin Grasslands and Xilin Gol Grasslands had increasing trends with the vegetation had degrading trends.

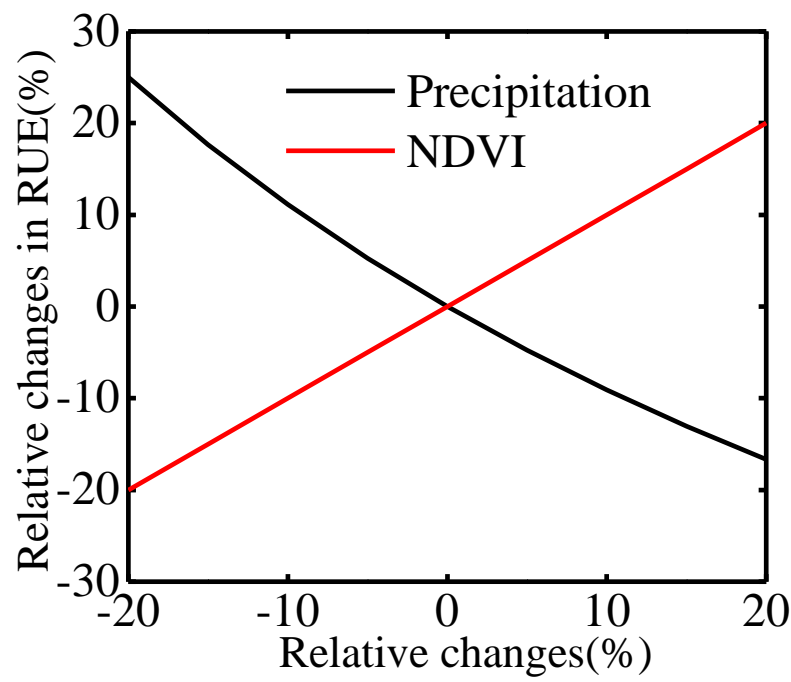

Figure 11. The sensitivity of RUE to precipitation and NDVI in Northwestern China during the period 1982-2013.

\section{Discussion}

Grassland restoration and degradation is a hot issue in arid and semi-arid areas. In our studies, we found that the vegetation restoration might have happened along with the land degradation in Northwestern China. The results are in accord with previous studies. For example, Yang [39] studied 
the NDVI of natural grasslands in Qinghai Province and found that the increasing and decreasing regions of NDVI in Qinghai Province coexisted, and the increase was much larger than the decrease from 1982 to 2003 . Vicente-Serrano et al. [51] showed that many natural and man-made factors can also have an impact on land degradation in semi-arid regions of the world using long time-series of remote sensing images and the NDVI for the period 1981 to 2011 . Kouba et al. [52] investigated the influence of increasing anthropogenic pressure on land degradation in highly vulnerable semi-arid environments in the Mediterranean region. The changing trends of NDVI for the HCG, MCG, and LCG in Northwestern China were also similar to previous studies. For example, Cao et al. [53] found that the grassland degradation in northern Tibet was still relatively serious from 2000 to 2010. The area of degraded grassland accounts for $58.2 \%$ of the whole area, and the proportion of heavily degraded and heavily degraded grassland areas were $19.0 \%$ and $6.5 \%$ by 2010 , respectively. Liu et al. [54] reported that the areas of high and medium vegetation coverage showed an increasing trend, while the area of low vegetation coverage areas showed a decreasing trend in Qinghai Province from 2002 to 2015. Zhang et al. [55] analyzed the difference between the years of 1982-2000 and 1982-2013, and they found that the vegetation had restored trends in the Qinghai-Tibetan Plateau during the period between 1982-2000, while the vegetation had degraded since the year 2000 in the Northern Tibetan Plateau where the low-coverage grasslands are distributed. The results are very similar to our findings in this study that the vegetation degraded seriously in the low coverage grassland.

In many areas, temperature and precipitation are generally considered to be the two major environmental variables that produce vegetation and NDVI spatial gradients [56]. As many studies have shown, the warmth of the growing season is the dominant factor in plant species composition and vegetation production between high latitudes [57-59]. The quantification of NDVI's integrated spatial and temporal environmental drivers expands our understanding of landscape level changes in vegetation assessed by remote sensing [60]. Previous studies suggested that for arid and semi-arid areas, increasing pre-season temperature could reduce water availability by increasing evaporation, thereby delaying the season onset [61]. Changes in vegetation productivity are mainly determined by climate change [62,63]. Bobkov et al. [64] reported that there was a statistically positive correlation between NDVI and spring and autumn temperatures of various vegetation types in the experimental area. Coniferous forests, that is, pine forests on poor soils, have the weakest correlation, and grassland and marsh are the most relevant. Some scholars have studied the NDVI of the Southwestern Romania forest ecosystem, pointing out that the annual average temperature and precipitation fluctuations directly affect the ecological quality of forest ecosystems [65]. The RUE is a useful indicator to reveal the dynamic response of precipitation to the change of vegetation in arid and semi-arid regions. In previous studies, Yan et al. [66] found that RUE is positively influenced by climate warming, but negatively affected by biofuel harvest in tall grass prairies of the Great Plains. These findings highlight the important roles of plant community structure and temporal distribution of precipitation in regulating ecosystem RUE. Mu et al. [67] reported that the inter-annual fluctuation of the RUE was negatively correlated with the annual precipitation in the arid areas, while it was strongly correlated with the annual temperature in Northwestern China from 2001 to 2010. Moreover, some research also discussed the response of RUE to the vegetation restoration/degradation and climate change. For example, Zhang et al. [22] found that RUE was in good relations to vegetation degradation, the more severe the degradation of vegetation, the lower the RUE and the improvement of vegetation restoration, and the RUE showed increasing trends in the Loess Plateau from 2000 to 2014. Holm et al. [18] used the NOAA satellite data to compare simulated estimates with total plant mass estimated by remote sensing and RUE, he thought that the dynamic changes in RUE can provide measurements of ecological degradation/recovery on a spatial scale. While Du et al. [68] reported that the RUE was opposite to the change of annual mean precipitation and they thought that the rapid increase or decrease of precipitation may cause pseudo-ecological restoration/degradation in a given ecosystem. The results were in accord with our research. Gamoun [25] thought that understanding how rainfall affects ranching productivity is crucial to predicting the effects of land degradation on the functioning of these 
ecosystems on desert pastures in Tunisia. Mclendon et al. [69] revealed that vegetation preferentially used precipitation-derived soil moisture, even with abundant groundwater. Kundu et al. [29] used RUE to monitor vegetation degradation, and substantially, the process of desertification in western Rajasthan. These results are also in accord with ours. Therefore, the RUE can be considered as a useful tool for assessing s of semi-arid rangeland vegetation [70,71].

However, there are different points of view. In general, RUE tends to decrease with increasing aridity and potential evapotranspiration, both of which are closely related to ecosystem-level water balance. Some previous studies also showed that drier sites tend to have lower and less variable RUE because of low plant density, low production potential, high evaporation potential, and high tolerance to water stress [72]. In contrast to our results, warming has been reported to decrease grassland RUE as a result of reduced plant production [73]. These observations are reasonable because the differences in plant species composition, soil texture, and water retention capacity of different grasslands affect the production of grassland under climate warming. For example, Shen [74] pointed out that the redistribution of precipitation caused by topographic factors may be one of the reasons for the high RUE of vegetation in the Taklamakan Desert. Jobbagy et al. [75] thought that the RUE of the ecosystem might be higher due to the developed root system of the plant and the higher production per unit of water consumed in the arid region. Meanwhile, some research revealed that RUE may be affected by the species composition of the community. Because they thought that there were certain $\mathrm{C}_{4}$ super xerophytes in extremely arid regions where $\mathrm{C}_{4}$ plants had lower transpiration rates and higher photosynthetic rates in arid environments, therefore, the RUE may also be higher [67,76]. In our study, the Taklimakan Desert is surrounded by Tianshan Mountains and the Kunlun Mountains, and the supply of ice and snow melting water makes the grassland vegetation on the edge of the desert grow well and had higher RUE value.

\section{Conclusions}

In this paper, the spatial and temporal changes of RUE and its response to the vegetation restoration/degradation in Northwestern China from 1982 to 2013 were analyzed by using the satellite-based NDVI and in situ meteorological data. The main conclusions drawn from this study are summarized as follows:

(1) Although the grassland areas have decreased gradually in Northwestern China during the past 30 years, the NDVI showed that the vegetation had obvious restoration as a whole in most grasslands. The grassland areas in Northwestern China has decreased by 25,187 $\mathrm{km}^{2}$ from 1990 to 2010 , and the proportion of the vegetation restoration was as high as $56.87 \%$, of which $30.92 \%$ was significant.

(2) The trends of RUE for all the grasslands showed increases in the east of Northwestern China and decreases in the west of Northwestern China. However, the RUE for the high-coverage grasslands showed a significant increasing trend and the RUE for the low-coverage grasslands showed significant decreasing trends over the past 30 years.

(3) There were good relationships between the RUE, vegetation restoration/degradation, and climate change (reflected by changes in air temperature and precipitation) in Northwestern China. The RUE for the grasslands was positively correlated with air temperature, while it was negatively corrected with the change of mean annual precipitation. Moreover, the RUE was more sensitive to the changes in precipitation and vegetation restoration/degradation. The obvious RUE increasing trends can be found in the vegetation restoration areas, while the RUE decreasing trends appeared in the vegetation degradation areas as a whole.

Water shortage in arid/semi-arid regions is becoming more serious due to various factors under global warming. The vegetation degradation and deteriorative land cover conversions might be facing more challenges with the temperature increasing. Our findings could contribute to the mechanical 
understanding of carbon and hydrological circulations in dry land ecosystems and offer evidence to future RUE research development and improvement.

Author Contributions: Z.Z. provides the datasets including the required supporting geoinformation software needed for the analyses; S.C., X.C., and Y.C. cooperated in designing and improving the concept of the research project and related processes; J.C. and J.T. conducted the data processing and analysis. All the authors participated actively in preparing and reviewing the manuscript.

Acknowledgments: This paper is financially supported by the China National Key R\&D Program during the 13th Five-year Plan Period (Grant No. 2017YFC0406100) and Distinguished Young Scholars Fund of Nanjing Forestry University (NLJQ2015-01) and the Six Talent Peaks project in Jiangsu Province (Grant no. 2015-JY-017). We would like to thank the National Climate Centre in Beijing for providing valuable climate datasets.

Conflicts of Interest: The authors declare no conflict of interest.

\section{References}

1. Deng, C.; Bai, H.; Gao, S.; Liu, R.; Ma, X.; Huang, X.; Meng, Q. Spatial-temporal variations of the vegetation coverage in Qinling Mountain and its dual response to climate change and human activities. J. Nat. Resour. 2017, 33, 425-438.

2. Zhang, T.; Zhang, M.; Duo, F. Analyses on vegetation time-space dynamics in northwestern China and its effect factor. Plateau Meteorol. 2010, 29, 1148-1152.

3. Asrar, G.; Fuchs, M.; Kanemasu, E.T.; Hatfield, J.L. Estimating Absorbed Photosynthetic Radiation and Leaf Area Index from Spectral Reflectance in Wheat. Agron. J. 1984, 76, 300-306. [CrossRef]

4. Eastman, J.R.; Sangermano, F.; Machado, E.A.; Rogan, J.; Anyamba, A. Global Trends in Seasonality of Normalized Difference Vegetation Index (NDVI), 1982-2011. Remote Sens. 2013, 5, 4799-4818. [CrossRef]

5. Laidler, G.J.; Treitz, P.M.; Atkinson, D.M. Remote Sensing of Arctic Vegetation: Relations between the NDVI, Spatial Resolution and Vegetation Cover on Boothia Peninsula, Nunavut. Arctic 2008, 61, 1-13. [CrossRef]

6. Suzuki, R.; Nomaki, T.; Yasunari, T. Spatial distribution and its seasonality of satellite-derived vegetation index (NDVI) and climate in Siberia. Int. J. Climatol. 2010, 21, 1321-1335. [CrossRef]

7. Ma, M.; Jiao, Y.; Cheng, G. Change in Land Coverage in Northwest China During the Past Decade Monitored by NOAA-CHAIN. J. Glaciol. Geocryol. 2002, 24, 68-72.

8. Ma, M.; Dong, L.; Wang, X. Study on the Dynamically Monitoring and Simulating the Vegetation Cover in Northwest China in the Past 21 Years. J. Glaciol. Geocryol. 2003, 25, 232-236.

9. Zhou, W.; Wang, Q.; Zhang, C.; Li, J. Spationtemporal variation of grassland vegetation NDVI in the middle and reaches of the Hei River and its response to climatic factors. Acta Pratacult. Sin. 2013, 22, 138-147.

10. Hou, M.; Zhao, H.; Wang, Z.; Yan, X. Vegetation responses to climate change by using the satellite-derived normalized difference vegetation index: A review. Clim. Environ. Res. 2013, 18, 353-364.

11. Li, Z.; Yan, F.; Fan, X. The variability of NDVI over northweat China and its relation to temperature precipitation. J. Remote Sens. 2005, 9, 208-313.

12. Chen, H.; Liu, Y.; Du, Z.; Liu, Z.; Zou, C. Tne Changes of Growing Sseason of the Vegetation in Huang-Huaihe-Haihe Region and Its Response to Climate Change. J. Appl. Meteorol. Sci. 2011, 22, 4377-4444.

13. Wei, Z.; Wang, D.; Zhang, C.; Liu, X.; Zhang, H. Response of vegetation cover to climate change and human activities in Northwest China during 1999-2010. J. Desert Res. 2014, 34, 1665-1670.

14. Prince, S.D.; Wessels, K.J.; Tucker, C.J.; Nicholson, S.E. Desertification in the Sahel: A reinterpretation of a reinterpretation. Glob. Chang. Biol. 2007, 13, 1308-1313. [CrossRef]

15. Wessels, K.J.; Prince, S.D.; Malherbe, J.; Small, J.; Frost, P.E.; Vanzyl, D. Can human-induced land degradation be distinguished from the effects of rainfall variability? A case study in South Africa. J. Arid Environ. 2007, 68, 271-297. [CrossRef]

16. Chen, Y.; Li, J.; Ju, W.; Ruan, H.; Qin, Z.; Huang, Y.; Jeelani, N.; Padarian, J.; Propastin, P. Quantitative assessments of water-use efficiency in Temperate Eurasian Steppe along an aridity gradient. PLOS ONE 2017, 12, e179875. [CrossRef] [PubMed]

17. Sala, O.E.; Parton, W.J. Primary Production of the Central Grassland Region of the United States. Ecology 1988, 69, 40-45. [CrossRef] 
18. Holm, A.M.; Cridland, S.W.; Roderick, M.L. The use of time-integrated NOAA NDVI data and rainfall to assess landscape degradation in the arid shrubland of Western Australia. Remote Sens. Environ. 2003, 85, 145-158. [CrossRef]

19. Bhandari, J.; Pan, X.; Bijaya, G.C.D. Spatial and Seasonal Variation in Rain Use Efficiency in Semiarid Grasslands of Inner Mongolia. Adv. Meteorol. 2015, 2015, 1-7. [CrossRef]

20. Sahnoun, M.H.; Fuller, D.O. Monitoring Rain-use Efficiency in southern Tunisia with Modis Level 2G. In Proceedings of the AGU Spring Meeting Abstracts 2002, Washington, DC, USA, 28-31 May 2002.

21. Zhang, C.; Liang, C.; Long, X.J.; Wei, R. Estimating and dynamic change of vegetation water use efficiency in Yangtze and Yellow River headwater regions. Trans. Chin. Soc. Agric. Eng. 2013, 29, 146-155.

22. Zhang, Y.; Wang, S. Spatial pattern of vegetation rainfall use efficiency and its response to vegetation change on the Loess Plateau. Arid Land Geogr. 2017, 40, 138-146.

23. Hountondji, Y.; Sokpon, N.; Nicolas, J.; Ozer, P. Ongoing desertification processes in the sahelian belt of West Africa: An evidence from the rain-use efficiency. In Recent Advances in Remote Sensing and Geoinformation Processing for Land Degradation; Rpder, A., Hill, J., Eds.; CRC Press/Balkema: London, UK, 2009; pp. 173-186.

24. Webb, W.L.; Lauenroth, W.K.; Szarek, S.R.; Kinerson, R.S. Primary production and abiotic controls in forests, grasslands, and desert ecosystems in the United States. Ecology 1983, 64, 134-151. [CrossRef]

25. Gamoun, M. Rain use efficiency, primary production and rainfall relationships in desert rangelands of Tunisia. Land Degrad. Dev. 2016, 27, 738-747. [CrossRef]

26. Mi, Z.; Chen, L.; Zhang, Z.; He, J. Alpine grassland water use efficiency based on annual precipitation, growing season precipitation and growing season evapotranspiration. Chin. J. Plant Ecol. 2015, 39, 649-660.

27. Wang, S. Study on Eco-hydrological Patterns based on Determination of Net Primary Production and Rainfall Use Efficiency across the Tao River Basin. Master's Thesis, Lanzhou University, Lanzhou, China, 2016.

28. Zhang, Y.; Su, H.; Zhang, X. Spatial and temporal analysis of vegetation cover change in the Yellow River basin from 1998 to 2012. J. Desert Res. 2014, 24, 597-602.

29. Kundu, A.; Patel, N.R.; Saha, S.K.; Dutta, D. Desertification in western Rajasthan (India): An assessment using remote sensing derived rain-use efficiency and residual trend methods. Nat. Hazards 2017, 86, 297-313. [CrossRef]

30. Huxman, T.E.; Smith, M.D.; Fay, P.A.; Knapp, A.K.; Shaw, M.R.; Loik, M.E.; Smith, S.D.; Tissue, D.T.; Zak, J.C.; Weltzin, J.F. Convergence across biomes to a common rain-use efficiency. Nature 2004, 429, 651-654. [CrossRef] [PubMed]

31. Paruelo, J.M.; Lauenroth, W.K.; Burke, I.C.; Sala, O.E. Grassland Precipitation-Use Efficiency Varies across a Resource Gradient. Ecosystems 1999, 2, 64-68. [CrossRef]

32. Wessels, K.J.; Prince, S.D.; Small, J. Monitoring land degradation in Southern Africa based on net primary productivity. In Proceedings of the 2003 IEEE International Geoscience and Remote Sensing Symposium, Toulouse, France, 21-25 July 2003; pp. 3305-3307.

33. Wang, Y.; Zhang, J.; Si, Z. Causes for degradation of grassland resources and measures for recovering of grassland ecosystem in Gansu Province. Chin. Agric. Sci. Bull. 2006, 22, 495-498.

34. Qi, Y.; Han, J. Grassland degradation causation and countermeasures for eco-environment rehabilitation in arid and semi- arid regions in Northwest China. Chin. J. Anim. Husb. 2008, 44, 44-45.

35. Xu, J.; Song, L.; Zhao, Z.; Hu, Y.; Liu, C. Monitoring grassland degradation dynamically at Maduo County in source region of Yellow River in past 15 years based on remote sensing. Arid Land Geogr. 2012, 35, 615-622.

36. Xian, W.; Xiang, Z.; Tao, S.; Shao, H. RS monitoring on grassland degradation in headwaters region of Northeastern Sichuan. Sci. Surv. Mapp. 2015, 40, 49-53.

37. Cui, X. Remotely Sensed Monitoring and Classification Management of Grassland in the Gannan Region, China. Ph.D. Thesis, Lanzhou University, Lanzhou, China, 2011.

38. $\mathrm{Xu}, \mathrm{S}$. Spatial-Temporal Change of Vegetation in the Western Songliao Plain based on NDVI and RUE. Master's Thesis, Northeast Normal University, Changchun, China, 2013.

39. Yang, Y. Temporal and Spatial Analysis of NDVI Variation and Correlation Analysis between NDVI and Temperature and Rainfall in the Natural Grassland of Qinghai Province. Master's Thesis, NanJing University of Information Science\&Technology, Nanjing, China, 2008.

40. Zheng, B.; Tian, Z.; Wang, W.; Li, Z. Analysis of recent land usage and survey in western China. Acta Ecol. Sin. 2004, 24, 1078-1085. 
41. Bai, Y.; Wu, J.; Xing, Q.; Pan, Q.; Huang, J.; Yang, D.; Han, X. Primary production and rain use efficiency across a precipitation gradient on the Mongolia Plateau. Ecology 2008, 89, 2140. [CrossRef] [PubMed]

42. Zhang, C.; Ren, Z.; Yuan, X. Intra-annual response of NDVI to changes in temperature and precipitation and its spatial characteristics in northwest China. Resour. Sci. 2011, 33, 2356-2361.

43. Dai, S.; Zhang, B.; Wang, H. Spatio-temporal change of vegetation index NDVI in Northwest China and its influencing factors. J. Eco-Inf. Sci. 2010, 12, 315-321. [CrossRef]

44. Piao, S.; Cui, M.; Chen, A.; Wang, X.; Ciais, P.; Liu, J.; Tang, Y. Altitude and temperature dependence of change in the spring vegetation green-up date from 1982 to 2006 in the Qinghai-Xizang Plateau. Agric. For. Meteorol. 2011, 151, 1599-1608. [CrossRef]

45. Chu, H.; Venevsky, S.; Wu, C.; Wang, M. NDVI-based vegetation dynamics and its response to climate changes at Amur-Heilongjiang River Basin from 1982 to 2015. Sci. Total Environ. 2019, 650, 2051-2062. [CrossRef] [PubMed]

46. Wessels, K.J.; Prince, S.D.; Zambatis, N.; MacFadyen, S.; Frost, P.E.; Van Zyl, D. Relationship between herbaceous biomass and 1- $\mathrm{km}^{2}$ Advanced Very High Resolution Radiometer (AVHRR) NDVI in Kruger National Park, South Africa. Int. J. Remote Sens. 2006, 27, 951-973. [CrossRef]

47. Fensholt, R.; Rasmussen, K. Analysis of trends in the Sahelian 'rain-use efficiency' using GIMMS NDVI, RFE and GPCP rainfall data. Remote Sens. Environ. 2011, 115, 438-451. [CrossRef]

48. Xu, C.; Teknisk-naturvetenskapliga, V.; Uppsala, U.; Geovetenskapliga, S.; Institutionen, F.G. Statistical analysis of parameters and residuals of a conceptual water balance model-Methodology and case Study. Water Resour. Manag. 2001, 15, 75-92. [CrossRef]

49. Wang, Y.; Xie, J.; Guo, X. Application of geostatistic interpolation method in ArcGIS. Softw. Guid. 2008, 34, 36-38.

50. Xu, C.; Gong, L.; Jiang, T.; Chen, D.; Singh, V.P. Analysis of spatial distribution and temporal trend of reference evapotranspiration and pan evaporation in Changjiang (Yangtze River) catchment. J. Hydrol. 2006, 327, 81-93. [CrossRef]

51. Vicente-Serrano, S.; Cabello, D.; Tomás-Burguera, M.; Martín-Hernández, N.; Beguería, S.; Azorin-Molina, C.; Kenawy, A. Drought variability and land degradation in semiarid regions: Assessment using remote sensing data and drought indices (1982-2011). Remote Sens. 2015, 7, 4391-4423. [CrossRef]

52. Kouba, Y.; Gartzia, M.; El Aich, A.; Alados, C.L. Deserts do not advance, they are created: Land degradation and desertification in semiarid environments in the Middle Atlas, Morocco. J. Arid Environ. 2018, 158, 1-8. [CrossRef]

53. Cao, X.; Ganjurjav, H.; Liang, Y.; Gao, Q.; Li, Y.; Wan, Y.; Danjiu, L. Temporal and spatial distribution of grassland degradation in northern Tibet based on NDVI. Acta Pratacult. Sin. 2016, 25, 1-8.

54. Liu, X.; Gao, X.; Ma, Y. The spatio-temporal evolution characteristics of vegetation distribution during the periods of 2002-2015 in Qinghai province, China. Arid Zone Res. 2017, 34, 1345-1352. [CrossRef]

55. Zhang, Z.; Chang, J.; Xu, C.; Zhou, Y.; Wu, Y.; Chen, X.; Jiang, S.; Duan, Z. The response of lake area and vegetation cover variations to climate change over the Qinghai-Tibetan Plateau during the past 30 years. Sci. Total Environ. 2018, 635, 443-451. [CrossRef] [PubMed]

56. Walden, V.P.; Mahesh, A.; Warren, S.G. Comment on "Recent changes in the North American Arctic boundary layer in winter" by R. S. Bradley et al. J. Geophys. Res. Atmos. 1996, 101, 7127-7134. [CrossRef]

57. Oechel, W.C.; Vourlitis, G.L.; Hastings, S.J.; Zulueta, R.C.; Hinzman, L.; Kane, D. Acclimation of ecosystem $\mathrm{CO}_{2}$ exchange in the Alaskan Arctic in response to decadal climate warming. Nature 2000, 406, 978-981. [CrossRef] [PubMed]

58. Epstein, H.E.; Walker, M.D.; Iii, F.S.C.; Starfield, A.M. A Transient, Nutrient-Based Model of Arctic Plant Community Response to Climatic Warming. Ecol. Appl. 2000, 10, 824-841. [CrossRef]

59. Stow, D.A.; Burns, B.H.; Hope, A.S. Spectral, spatial and temporal characteristics of Arctic tundra reflectance. Int. J. Remote Sens. 1993, 14, 2445-2462. [CrossRef]

60. Campo-Bescós, M.A.; Muñoz-Carpena, R.; Southworth, J.; Zhu, L.; Waylen, P.R.; Bunting, E. Combined spatial and temporal effects of environmental controls on long-term monthly NDVI in the Southern Africa Savanna. Remote Sens. 2013, 5, 6513-6539. [CrossRef]

61. Ganguly, S.S.G.C. Global Data Sets of Vegetation Leaf Area Index (LAI)3g and Fraction of Photosynthetically Active Radiation (FPAR)3g Derived from Global Inventory Modeling and Mapping Studies (GIMMS) Normalized Difference Vegetation Index (NDVI3g) for the Period 1981 to 2011. Remote Sens. 2013, 5, 927-965. 
62. Piao, S.; Friedlingstein, P.; Ciais, P.; Zhou, L.; Chen, A. Effect of climate and $\mathrm{CO}_{2}$ changes on the greening of the Northern Hemisphere over the past two decades. Geophys. Res. Lett. 2006, 33, 265-288. [CrossRef]

63. Angert, A.; Biraud, S.; Bonfils, C.; Henning, C.C.; Buermann, W.; Pinzon, J.; Tucker, C.J.; Fung, I. Drier summers cancel out the $\mathrm{CO}_{2}$ uptake enhancement induced by warmer springs. Proc. Natl. Acad. Sci. USA 2005, 102, 10823-10827. [CrossRef] [PubMed]

64. Bobkov, A.; Panidi, E.; Torlopova, N.; Tsepelev, V. NDVI dynamics of the taiga zone in connection with modern climate changes. Int. Arch. Photogramm. Remote Sens. 2015, XL-7/W3, 157-163. [CrossRef]

65. Pravalie, R.; Sîrodoev, I.; Peptenatu, D. Detecting climate change effects on forest ecosystems in Southwestern Romania using Landsat TM NDVI data. J. Geogr. Sci. 2014, 24, 815-832. [CrossRef]

66. Yan, L.; Luo, Y.; Sherry, R.A.; Bell, J.E.; Zhou, X.; Xia, J. Rain use efficiency as affected by climate warming and biofuel harvest: Results from a 12-year field experiment. Gcb Bioenergy 2014, 6, 556-565. [CrossRef]

67. Mu, S.; You, Y.; Zhu, C.; Zhou, K. Spatio-temporal patterns of precipitation-use efficiency of grassland in Northwestern China. Acta Ecol. Sin. 2017, 37, 1458-1471.

68. Du, J.; Shu, J.; Zhang, L. Analysis of ecosystem degradation and recovery using precipitation use efficiency and NDVI in the headwater catchment of the Yellow River basin. Acta Ecol. Sin. 2012, 32, 3404-3413.

69. McLendon, T.; Hubbard, P.J.; Martin, D.W. Partitioning the use of precipitation- and groundwater-derived moisture by vegetation in an arid ecosystem in California. J. Arid Environ. 2008, 72, 986-1001. [CrossRef]

70. Lehouerou, H.N. Rain-Use Efficiency: A Unifying Concept in Arid-Land Ecology. J. Arid Environ. 1984, 7, 213-247.

71. Day, T.A.; Detling, J.K. Water Relations of Agropyron smithii and Bouteloua gracilis and Community Evapotranspiration Following Long-term Grazing by Prairie Dogs. Am. Midl. Nat. 1994, 132, 381-392. [CrossRef]

72. Du, L.; Mikle, N.; Zou, Z.; Huang, Y.; Shi, Z.; Jiang, L.; Mccarthy, H.R.; Liang, J.; Luo, Y. Global patterns of extreme drought-induced loss in land primary production: Identifying ecological extremes from rain-use efficiency. Sci. Total Environ. 2018, 628-629, 611-620. [CrossRef] [PubMed]

73. Boeck, H.H.D.; Lemmens, C.M.H.M.; Bossuyt, H.; Malchair, S.; Carnol, M.; Merckx, R.; Nijs, I.; Ceulemans, R. How do climate warming and plant species richness affect water use in experimental grasslands? Plant Soil 2006, 288, 249-261. [CrossRef]

74. Shen, Y. Tianshan Mountain is a hot spot for global climate change and water cycle changes in Central Asia. J. Glaciol. Geocryol. 2009, 31, 780.

75. Jobbagy, E.G.; Sala, O.E. Controls of Grass and Shrub Aboveground Production in the Patagonian Steppe. Ecol. Appl. 2000, 10, 541-549. [CrossRef]

76. Ehleringer, J.R.; Cerling, T.E.; Helliker, B.R. C4 photosynthesis, Atmospheric $\mathrm{CO}_{2}$. Oecologia 1997, 112, 285-299. [CrossRef] [PubMed]

(C) 2018 by the authors. Licensee MDPI, Basel, Switzerland. This article is an open access article distributed under the terms and conditions of the Creative Commons Attribution (CC BY) license (http://creativecommons.org/licenses/by/4.0/). 